\title{
Acordes y disonancias en legislación educativa entre nación y provincias desde el caso Neuquén
}

\section{Chores and Disonantes in Education Legislation between Nation and Province from Neuquén Case}

\author{
Héctor Rubén Cucuzza ${ }^{1}$ \\ Universidad Nacional de Educación (Argentina)
}

Recibido: 11-04-17

Aprobado: 20-04-17

\section{Resumen}

El artículo compara tres documentos legislativos de Argentina: la ley de Educación Nacional (2006), el Proyecto de Ley No. 7319 (2011) y la Ley Orgánica de Educación (2014), ambos de la Provincia del Neuquén; sobre cinco puntos que configuraron los sistemas educativos nacionales desde el siglo XIX: laicidad, educación común, obligatoriedad, gratuidad y gradualidad, en pos del objetivo de la alfabetización universal.

Se realiza una breve contextualización histórica del problema, se compara su tratamiento en los tres documentos y se realizan algunas consideraciones a modo de síntesis y prospectiva.

En el cierre se advierte sobre los riesgos de la descentralización si conduce a la fragmentación resultante de las polémicas transferencias de los noventa realizadas en consonancia con las políticas privatizadoras fundadas

\footnotetext{
${ }^{1}$ (rubencucuzza@gmail.com). Profesor Emérito Universidad Nacional de Luján (Argentina). Sus últimas últimas han sido: "La doctrina, la liturgia y los ejercicios espirituales. Los cuadernos escolares en la religiosidad patriótica laica”. En MEDA, Juri; MONTINO, Davide y SANI, Roberto (eds.) School ExerciseBooks. A in ComplexSourcefor a History of theApproach to Schooling and Educationthe 19th and 20th Centuries, Edizioni Polistampa, Firenze, Italia, 2010, Vol. I, pp. 279296. "El Proyecto Histelea: nuevas aperturas teóricas y desafíos metodológicos", en Magis. Revista Internacional de Investigación en Educación, Universidad Javeriana, Colombia, 4 (7), 2011, pp. 45 66. Historia de la lectura en Argentina. Del catecismo colonial a las netbooks estatales, director autor, Editoras del Calderón, Buenos Aires, 2012.
} 
en las concepciones de la subsidiariedad del Estado. Aunque permiten ensayar propuestas alternativas particulares regionales y la apertura de un amplio margen de acción a las jurisdicciones provinciales.

Palabras-clave: Argentina-Legislación-Educación-Nación-ProvinciaNeuquén.

\section{Abstract}

The article compares three legislative documents of Argentina: the law of national education (2006), the draft law No. 7319 (2011) and the organic law of education (2014), both from the province of Neuquén; about five points that shaped the national education systems since the nineteenth century: secularism, common education, compulsory, free and gradualism, in pursuit of the goal of universal literacy.

$\mathrm{He}$ is a brief historical contextualization of the problem, compare ditstreatment in the three documents, and make some considerations by way of synthesis and prospective.

Closing warns about the risks of decentralization ifit leads to there sulting fragmentation of the controversial 1990s transfers made in line with the privatization policies found edon the concepts of subsidiarity of the State. Thought hey allow to test alternative proposals regional individuals and the opening of a wide range of action to provincial jurisdictions.

Key-words: Argentina-Legislation-Education-Nation-Province-Neuquén

“...en los orígenes del sistema educativo hay una marca indeleble [que] se expresa en la creación de un dispositivo estratégico de inclusión asociado a procesos excluyentes" (Brener y Galli 2016:12)

\section{Cuestiones introductorias}

El siguiente artículo es una versión revisada y ampliada del informe inédito que presentamos a la Honorable Legislatura de Neuquén en respuesta a la solicitud de su Presidenta Dra. Ana María Pechen para participar en el Foro Educativo Neuquino.

El informe se centra en el análisis de tres documentos: el Proyecto de Ley No. 7319 de 2011 de la Provincia del Neuquén, la Ley de Educación Nacional No 26.206 de 2006; a los que ahora agregamos, la Ley Orgánica de Educación de la Provincia de Neuquén sancionada finalmente en 2014. 
Valga como advertencia preliminar señalar que el artículo se apoya en la mirada de la Historia Social de la Educación, campo de estudio en el que venimos desarrollando nuestros trabajos en la Universidad Nacional de Luján.

Desde ese lugar procuramos realizar un análisis de las propuestas que dichos documentos realizan para el logro de la educación común por la obligatoriedad de la escolarización primaria en los modelos fundacionales; a la que se añade en nuestros días la educación inicial y secundaria.

Nos detendremos en particular en el surgimiento de la legislación eurooccidental de los sistemas educativos nacionales bajo un modelo de cinco puntas cuyos vértices eran los principios de: laicidad, escuela común, obligatoriedad, gratuidad, gradualidad; cinco aspectos que organizarán este trabajo, colocando el centro en un breve recorrido histórico y detenernos luego en cómo fueron considerados dichos aspectos en los debates nacionales que condicionan y se hacen presentes en el debate del Proyecto neuquino y cómo fueron recogidos en la Ley Orgánica².

Para arribar a estas configuraciones legislativas tuvo lugar un sinuoso recorrido histórico nacional, de marchas y contramarchas, desde la Ley 1420 en 1884, por lo que los resultados expresaron asimetrías y desigualdades hasta la actualidad.

Desde mediados del Siglo XX fue posible advertir un crecimiento de las teorías pedagógicas, sociológicas y políticas procurando, explicar las posibles causas del incumplimiento de la utopía para encontrar luego las posibles estrategias políticas que permitieran subsanarlo.

Con diversos (y crecientes) grados de criticidad los discursos revisaron los cinco principios fundacionales mencionados, establecieron parámetros de comparación entre ellos e intentaron aportar explicaciones y políticas educativas alternativas.

Los debates se apoyaron, entre otras argumentaciones, en las consecuencias de los avances y retrocesos del aparato escolar laico frente a la Iglesia; y en las distintas interpretaciones acerca de las funciones de la obligatoriedad: al servicio de la democratización política, de la formación de fuerza de trabajo o de la redistribución del acceso al saber por parte de los sectores subalternos. En suma, el balance de los logros o fracasos en los principios de laicidad, obligatoriedad y gratuidad, desembocaban en posturas acerca del logro o del fracaso en la expansión de la escuela común.

\footnotetext{
${ }^{2}$ Obsérvese que, si bien enfocamos el trabajo en los principios fundantes en momentos de la constitución de los sistemas educativos nacionales a nivel eurooccidental, los mismos se mantuvieron y mantienen en los debates hasta la actualidad. No obstante nuevas categorías ingresan en las discusiones teóricas y en las legislaciones tales como equidad, calidad, inclusión, entre otros; aunque no serán consideradas en detalle aquí salvo que ameriten alguna referencia en relación con aquellos principios.
} 
Procuramos problematizar en especial, en articulación con los principios fundacionales, uno de los vértices escasamente trabajados, el que se refiere a la organización de los sistemas escolares en aulas graduadas que contienen cohortes de alumnos de la misma edad cronológica.

Se intentará debatir sobre su relativa incidencia como mecanismo interno de legitimación de desigualdades externas, y sus consecuencias, en última instancia, del premio del acceso y la promoción ascendente tanto como de la sanción y la exclusión en la apropiación de la cultura escrita.

La secuencia en el análisis no es azarosa sino que desde una lógica histórica comienza con el debate sobre la laicidad en el marco general de las disputas entre Estado vs Iglesia católica, porque en el interior de ese debate surgieron las otras propuestas estatales de educación común, y los límites que se le asignaban a la obligatoriedad y gratuidad en el acceso y permanencia dentro de los niveles y/o modalidades que adoptara la estructura del sistema. La gradualidad no mereció debates significativos aunque llevaba en sus reglas de organización de la escuela la mejor descripción posible, a nuestro juicio, de los mecanismos de la "caja negra", una metáfora elusiva sobre el funcionamiento interno de la escuela invocada con frecuencia en los estudios recientes de historia de la educación ${ }^{3}$.

La configuración de los sistemas educativos nacionales generó un aparato estatal cuya finalidad principal fue la alfabetización de grandes masas de población bajo la trilogía escuela-libro-democracia en el apogeo de la cultura tipográfica; cuestión que merece una atención especial en las tentativas actuales de reformulación del papel de la escuela en las nuevas condiciones que impone el desarrollo de las nuevas tecnologías eléctricas y electrónicas que se plantean en un mundo globalizado.

No obstante, este dispositivo estratégico de inclusión estuvo asociado a mecanismos excluyentes. Y este fenómeno paradojal de inclusión excluyente "se convierte en el nudo que debe desarmarse para encarar procesos de transformación verdaderos a través de una inclusión democrática de y en las escuelas" (Brener y Galli 2016:12).

\section{La cuestión de la laicidad}

\section{a) Breve contextualización histórica}

El laicismo en la escuela fue resultado histórico de las luchas empeñadas entre la Iglesia y el Estado durante siglos en occidente, que alcanzaron un punto

\footnotetext{
${ }^{3}$ Dominique Julia afirma que "[La historia de las disciplinas escolares] abre, em todo caso, para retomar uma metáfora aeronáutica, a "caixapreta" da escola, ao buscar compreender o que ocorre nesse espaço particular” (Julia 2001:13).
} 
culminante en el siglo XIX con la configuración de los sistemas educativos nacionales.

Las pujas por el control del aparato escolar se expresaron en todo el transcurso de la historia argentina desde los momentos fundacionales del siglo XIX, atraviesan todo el siglo XX y llegan hasta nuestros días, alcanzando diversos grados de virulencia según las épocas.

En esos orígenes en Argentina, la Ley 1420, en su artículo $8^{\circ}$, no se pronunció expresamente por el laicismo, aunque lo concretó de hecho al establecer que sólo después de las horas de clases, los ministros autorizados de los diferentes cultos estaban habilitados para impartir enseñanza religiosa.

La Iglesia Católica no cejó en sus reivindicaciones y obtuvo su eliminación en el proceso que se inicia con la Revolución del ' 43 y durante los primeros gobiernos peronistas con la inclusión de contenidos religiosos en el horario escolar y a cargo de los maestros del sistema.

Las mismas razones que llevaron al pacto originario Iglesia/ peronismo condujeron a su rompimiento en 1954: ambos actores invadieron simultáneamente el campo de producción simbólica del otro (Pitelli y Somoza Rodríguez 1997:107).

Una nueva tentativa eclesiástica se registró durante la presidencia de Arturo Frondizi en las movilizaciones masivas en pro y en contra de la enseñanza "libre o laica"; resurge durante la dictadura de Onganía y la gestión de José Mariano Astigueta hacia 1966 con la primera formulación de la reforma que recuperaba la reforma Saavedra Lamas resistida en nombre de la defensa del laicismo; y vuelve a expresarse y reaparece durante la gestión de Llerena Amadeo como ministro del así denominado Proceso de Reorganización Nacional iniciado con el golpe de Estado de 1976.

Desde la Ley Federal de Educación, sancionada en 1993 durante la presidencia de Carlos Menem hasta la ley actual de 2006, puede observarse un cierto equilibrio de fuerzas donde no aparecen menciones expresas a la laicidad, aunque se recogen las aspiraciones de la Iglesia al sindicar entre otros agentes del sistema, a la familia como "agente natural y primario" respecto de la educación de sus hijos.

\section{b) Comparación entre la Ley Nacional y el proyecto de Ley provincial 7319/2011}

Como señalamos, no hace mención expresa al principio de la laicidad la Ley de Educación Nacional y su artículo $6^{\circ}$ adopta la formulación elusiva que destacamos en el punto anterior acerca de la familia: 


\begin{abstract}
"El Estado garantiza el ejercicio del derecho constitucional de enseñar y aprender. Son responsables de las acciones educativas el Estado Nacional, las Provincias y la CIUDAD AUTÓNOMA DE BUENOS AIRES, en los términos fijados por el artículo $4^{\circ}$ de esta ley; los municipios, las confesiones religiosas reconocidas oficialmente y las organizaciones de la sociedad; y la familia, como agente natural y primario".
\end{abstract}

En cambio, aparece explícitamente mencionada la palabra laica en el artículo $4^{\circ}$ del proyecto No. 7319 o Ley Orgánica de Educación de la Provincia de Neuquén; apartándose llamativamente en este punto de la Ley nacional, junto a los principios que definen las políticas estatales, a saber:

"El Estado provincial, en materia de educación, debe asegurar, proveer y garantizar en todo su territorio, la aplicación de los siguientes principios: pública, laica, gratuita, obligatoria, inclusiva, equitativa, integral, con justicia social y calidad".

No obstante el artículo 11 parecería recoger una fórmula que procura licuar la antinomia estatal privada al afirmar que:

"El Estado provincial reconoce, autoriza, supervisa y regula el funcionamiento de las instituciones educativas estatales de gestión pública, privada y social." (Cursivas propias).

El tema es reforzado en el inciso a) del artículo 88 al referirse a los derechos y obligaciones de los padres, madres, tutores/as, facultándolos para:

"Elegir para sus hijos/as representados/as la institución educativa estatal de gestión pública, privada o social que responda a sus convicciones en el marco de la presente Ley y reglamentaciones vigentes".

Estas instituciones son reconocidas en el punto 3.8 del anexo I como "un derecho a la libertad de enseñanza y de libre opción para los padres de decidir la mejor educación para sus hijos".

\title{
c) Registro del problema en la Ley Orgánica 2945/2014
}

En su artículo $3^{\circ}$ recoge expresamente el principio de la laicidad:

"El Estado provincial debe asegurar, proveer y garantizar una educación pública, gratuita, laica, integral, permanente, inclusiva, científica, equitativa, con justicia social y de excelencia". 
Y en el artículo 29, inciso a) 1 reproduce la fórmula anterior citada del proyecto 7319 afirmando el derecho de los padres para elegir "la institución educativa estatal de gestión pública o privada que responda a sus convicciones"

\section{d) Síntesis y prospectiva en cuanto a la laicidad ${ }^{4}$}

a) negar los aspectos de la polémica que impliquen retroceder a las disputas entre la Iglesia y el Estado como agentes antinómicos en la educación en tanto saldo histórico heredado de las luchas entre las burguesías liberales y las concepciones eclesiásticas defensoras del antiguo régimen.

b) afirmar la neutralidad del Estado y el laicismo sobre las diferencias de credo como tentativa homogeneizadora de ciudadanía modernizante que relega las creencias religiosas al ámbito de la familia y las instituciones de los diversos cultos.

c) y superar el debate decimonónico generando instancias participativas de la comunidad, creyentes y no creyentes, en igualdad de estatus con prescindencia de las creencias religiosas particulares en el gobierno de la educación.

\section{La cuestión de la educación común}

\section{a) Breve contextualización histórica}

Por razones de síntesis sólo dejaremos indicado aquí que por "modelo fundacional", entendemos al de la Ley1420, "liberal", "positivista", "sarmientino" y remitimos a otros trabajos donde analizamos críticamente dichas categorías. (Cucuzza 1985:103-137). Del mismo modo nos excede largamente en este trabajo entrar en las profusas polémicas surgidas desde posiciones laudatorias o críticas sobre los resultados de dicho sistema fundacional siendo que la sola recuperación de los títulos en debate reactualiza polémicas no saldadas en nuestro país y Latinoamérica.

Comenzamos este apartado con una cita de Antonio Gramsci que realiza Juan Carlos Tedesco, en su texto clásico "Educación y Sociedad":

\footnotetext{
${ }^{4}$ La legislación educativa transparenta antinomias que atravesaron la historia de la educación argentina, desde el facúndico subtítulo de "Civilización vs Barbarie", hasta "Nación vs Provincias" o el "Escuelas comunes vs. Escuelas diferenciadas", entre otras.

Para intentar superar las antinomias en los apartados síntesis y prospectiva intentaremos proponer un ejercicio dialéctico en el sentido del "aufheben" hegeliano, no como en cierta versión escolar de los sucesivos momentos de afirmación, negación y negación de la negación, sino en el sentido del verbo alemán mencionado como simultaneidad de acciones aparentemente contradictorias tales como suspender, conservar y elevar.
} 


\begin{abstract}
“Antonio Gramsci planteó con agudeza este problema cuando afirmó que el carácter social de una escuela determinada consiste en que cada grupo posee su propio tipo de escuela para perpetuar a través, de ella, una función directiva o instrumental. La multiplicación de los distintos tipos de escuela profesional tiende pues a eternizar las diferencias tradicionales" (citado en Tedesco 2003:64).
\end{abstract}

La cita, es utilizada por Tedesco para afirmar su hipótesis sobre la finalidad política del sistema fundacional y apoyarse luego en la oposición a la Reforma Saavedra Lamas de 1916 que acotaba el camino hacia la universidad de los nacientes sectores de clase media generando distintos tipos de escuela para las distintas clases sociales bajo el argumento de la crítica al enciclopedismo libresco y la oferta de salidas laborales hacia el mundo del trabajo.(Mayochi y Van Gelderen 1969:80-85).

Más allá de las intenciones del autor un cierto "tedesquismo" atravesó buena parte de los debates en el siglo XX sobre el supuesto que toda reforma que favoreciera la segmentación reforzaría el monopolio del conocimiento; $\mathrm{y}$, en especial, las interpretaciones acerca de la configuración de un sistema paralelo de educación técnica, en particular la creación de la Universidad Obrera y el sistema de educación técnica gobernado por la CNAOP (Comisión Nacional de Aprendizaje y Orientación Profesional).

Dejaremos solamente indicado que las formas de segmentación que puede adoptar un sistema, sean ellas horizontales y encubiertas, o verticales en el sentido de limitar el acceso ascendente hacia niveles superiores de los sectores subalternos, se constituyen en una negación de la idea de educación común y en la causa principal de los conflictos por la democratización de la escuela.

Tal el caso de las estructuras segmentadas de la mencionada reforma Saavedra Lamas (retomada en una breve tentativa a comienzos de la dictadura de Onganía) y del primer peronismo, aunque dejamos abierto el debate para este último caso particular por su complejidad que excede los límites de este artículo. (Cucuzza 1997:128-134).

No obstante es posible advertir que la misma segmentación también puede reflejar las luchas de esos mismos sectores por el acceso a mayores niveles de educación cuando la mera proclamación formal de la educación común construye barreras internas que se expresan en el fracaso escolar, la repetición y el abandono, como veremos más adelante.

La segmentación horizontal se expresó (y se expresa) negando la igualdad de oportunidades implícita en la idea de educación común en diversas formas, entre otras: 
a) la diferenciación de género o de comunidades originarias,

b) en la generación de escuelas diferenciadas según clases o grupos sociales,

c) en las desiguales ofertas entre escuelas públicas y/o privadas,

d) en las diferencias urbano-rural y, más aún entre escuelas favorecidas y desfavorecidas en un mismo espacio urbano.

e) Históricamente entre las escuelas nacionales incluyendo a las Láinez y las escuelas provinciales. Y en la actualidad después de las transferencias de escuelas primarias y secundarias a las provincias, la segmentación entre provincias ricas y provincias pobres alcanza el grado de fragmentación.

Respecto del punto a) el proyecto No. 7319 se pronuncia en distintos apartados, por ejemplo, en el artículo 8, inciso a) y r) declara“"garantizar en el ámbito educativo la perspectiva de género y asegurar a los pueblos originarios el respeto a su lengua y a su identidad cultural.

En cuanto al segundo inciso del artículo 8, el proyecto se preocupa de incluirlo en el título referido a la Educación de Jóvenes y Adultos:

"Contemplar la diversidad cultural, respetar el saber tradicional y los diferentes sistemas de aprendizaje, preservar la sabiduría oral de los grupos minoritarios y de los pueblos originarios".

En el artículo 61 propone una expresa declaración de objetivos en el título sobre la Educación Intercultural (desarrollo que no aparece en cuanto a las diferenciaciones de género), a saber:

“a) Preservar, fortalecer y socializar pautas culturales, lenguas, cosmovisiones e identidades étnicas en tanto sujetos de derecho y protagonistas activos del desarrollo de la sociedad contemporánea.

b) Propiciar mecanismos de participación a través de sus representantes a los efectos de definir, ejecutar y evaluar las estrategias orientadas a esta modalidad.

c) Impulsar la investigación sobre la realidad sociocultural y lingüística de los pueblos originarios y migrantes, de los entornos rurales y urbanos, a los fines de su incorporación en el diseño curricular".

Sobre las desiguales ofertas entre educación pública y privada, nos preocupa que el artículo 5 del Título I recoja la polémica diferenciación "educación pública de gestión estatal” y "educación pública de gestión privada" que formó parte de los debates ideológicos de las tentativas de reforma durante la segunda mitad del siglo XX y persiste hasta nuestros días. Agrega, aunque sin definirlas, las escuelas de "gestión social". 


\section{b) Comparación entre la Ley Nacional y el proyecto de Ley provincial $7319 / 2011$}

Señala la Ley de la nación en su artículo 17 que:

"La estructura del Sistema Educativo Nacional comprende CUATRO (4) niveles -la Educación Inicial, la Educación Primaria, la Educación Secundaria y la Educación Superior-, y OCHO (8) modalidades.

A los efectos de la presente ley, constituyen modalidades del Sistema Educativo Nacional aquellas opciones organizativas y/o curriculares de la educación común, dentro de uno o más niveles educativos, que procuran dar respuesta a requerimientos específicos de formación y atender particularidades de carácter permanente o temporal, personales y/o contextuales, con el propósito de garantizar la igualdad en el derecho a la educación y cumplir con las exigencias legales, técnicas y pedagógicas de los diferentes niveles educativos".

Nos interesa detenernos en el tema de las modalidades por cuanto en distintos momentos históricos la diferenciación educativa tuvo su expresión en la adopción de modalidades diferentes por fuera del tronco común obligatorio. Dice la Ley nacional:

"Son modalidades: la Educación Técnico Profesional, la Educación Artística, la Educación Especial, la Educación Permanente de Jóvenes y Adultos, la Educación Rural, la Educación Intercultural Bilingüe, la Educación en Contextos de Privación de Libertad y la Educación Domiciliaria y Hospitalaria. Las jurisdicciones podrán definir, con carácter excepcional, otras modalidades de la educación común, cuando requerimientos específicos de carácter permanente y contextual así lo justifiquen".

Observamos que el Proyecto neuquino no se aparta de las prescripciones nacionales sobre la estructura del sistema aunque redefine sus modalidades en su artículo 14:

"El Sistema Educativo estatal de gestión pública, privada o social está conformado por:

a) Niveles: Educación Inicial, Educación Primaria, Educación Secundaria y Educación Superior.

b) Modalidades: Educación Técnico Profesional, Educación Artística, Educación a Personas con Discapacidad, Formación Profesional, Educación Física, Educación de Jóvenes y Adultos, Educación Intercultural y Educación Domiciliaria y Hospitalaria.

c) Ámbitos de desarrollo: Educación Urbana, Educación Rural, Educación en contexto de Encierro y Educación a Distancia con Componente Virtual.

d) Contenidos Curriculares Transversales y Obligatorios: Educación Ambiental, Educación Vial, Educación en Ejercicio de la Ciudadanía y Derechos Humanos, 
Educación para la Salud Sexual y Reproductiva, Educación en Cooperativismo, Educación para el Consumo y la Producción, y Educación para la Ciencia y la Tecnología".

En ambos casos, si bien no se hace referencia explícita a los términos "educación común" parecerían incluidos en los términos de la estructura general del sistema ligados a la obligatoriedad escolar.

Las modalidades atenderían las cuestiones relativas a la orientación vocacional pero no constituyen establecimientos separados de la escuela secundaria.

\section{c) Registro del problema en la Ley Orgánica 2945/2014}

Se destacan las siguientes referencias en el capítulo único de fines y objetivos del título III que se dirigen a garantizar la "educación común":

e) Garantizar la inclusión educativa, a través de políticas universales y de estrategias pedagógicas y de asignación de recursos que otorguen prioridad a los sectores más desfavorecidos de la sociedad

f) Asegurar condiciones de igualdad, respetando las diferencias entre las personas, sin discriminación ni de género ni de ningún otro tipo.

g) Garantizar, a los pueblos originarios, el respeto por su lengua y su identidad cultural, promoviendo la valoración de la interculturalidad en la formación de todos los estudiantes.

h) Garantizar el acceso y las condiciones para la permanencia y el egreso de los diferentes niveles del Sistema Educativo, asegurando la gratuidad en las instituciones de gestión estatal, en todos los niveles y modalidades.

Y en su capítulo III la Ley Orgánica se refiere con algunas diferencias a las modalidades, incorporando a ellas los "ámbitos de desarrollo" del proyecto 7319:

“a) Niveles: 1. Educación Inicial. 2. Educación Primaria.3. Educación Secundaria.

4. Educación Superior.

b) Modalidades: 1. Educación Técnico-Profesional. 2. Educación Artística.

3. Educación Especial. 4. Educación permanente de Jóvenes y Adultos. 5.

Educación Intercultural. 6. Educación Domiciliaria y Hospitalaria. 7. Educación Rural. 8. Educación en Contextos de Privación de Libertad.

c) Contenidos curriculares transversales y obligatorios: 1. Educación para la observancia de los Derechos Humanos. 2. Educación para la observancia de la Constitución Nacional y la Constitución Provincial. 3. Educación para la ciencia y la tecnología. 4. Educación ambiental. 5. Educación para la salud sexual integral y reproductiva. 6. Educación vial. 7. Educación intercultural. 
8. Educación para la economía social. 9. Educación para el conocimiento de los derechos del consumidor. 10. Educación para la resolución alternativa de conflictos. 11. Educación para el fortalecimiento de la integración con los países latinoamericanos. 12. Educación para la prevención de la violencia escolar, familiar y de género. 13. Educación intergeneracional. 14. Educación para afianzar los derechos soberanos sobre las Islas Malvinas, Antártida e Islas del Atlántico Sur y los espacios marítimos circundantes. 15. Educación con perspectiva de género".

\section{d) Síntesis y prospectiva en cuanto a la educación común}

a) negar estructuras educativas heredadas del siglo XIX donde la escuela común era destinada a las "masas" mientras el Colegio Nacional y la Universidad se reservaban a la formación de cuadros dirigentes de la elite.

b) afirmar las concepciones de la educación común y el acceso inclusivo de todos los sectores sociales al sistema educativo en todos sus niveles y modalidades.

c) y superar los debates antinómicos entre "formación general humanista" vs "educación para el trabajo" en línea con las novísimas condiciones de la producción del conocimiento generadas por la revolución científico-tecnológica

\section{La cuestión de la obligatoriedad}

\section{a) Breve contextualización histórica}

En directa relación con la idea de educación común se encuentra la definición del nivel de obligatoriedad.

Así durante la primera mitad del siglo XX, la obligatoriedad estuvo vinculada a la escuela primaria de la Ley 1420, salvo el breve interregno de la Reforma Saavedra Lamas, cuando fue reducida a los primeros cinco años de ese nivel.

Esta última estructura fue recuperada cincuenta años más tarde en el Anteproyecto de 111 artículos de Onganía/Astigueta de 1968 pero las resistencias, en especial de los gremios docentes, llevaron al mismo gobierno a una nueva formulación haciendo extensiva la obligatoriedad a la escuela intermedia.

Llama la atención su recuperación una década después en el Anteproyecto de Ley Federal de Educación que permitía que las jurisdicciones pudieran elegir entre las siguientes estructuras "alternativas":

“a)unificación del nivel primario y del ciclo básico del nivel secundario a los 
fines de organizar un nivel básico general de nueve años; b) unificación del tercer ciclo del nivel primario y el ciclo básico del nivel secundario, a los fines de organizar un nivel intermedio de cuatro años; c) reducción del nivel primario en uno o dos años y extensión del nivel básico del nivel secundario en igual número de años" (Cantini 1981:192-193).

El planteo de la obligatoriedad escolar estuvo ligado a la formación de mano de obra de trabajo, a la prevención de la criminalidad y a la construcción de ciudadanía, entre otros factores.

En este último planteo el Congreso Pedagógico llegó a registrar una propuesta de voto calificado que relacionaba obligatoriedad-lectura-sufragio, propuesta que fue rechazada. Decía su propulsor Nicanor Larrain:

"Saber leer y escribir es una condición indispensable para el ejercicio del sufragio, y es por consecuencia una omisión de la ley nacional del 13 de noviembre de 1863 sobre el régimen electoral (citado por Cucuzza, 1986:49)".

Actualmente no registramos propuestas significativas en la dirección del voto calificado condicionado al dominio de la lectura y escritura, aunque en el discurso de determinados "bolsones de sentido común", se registran vinculaciones directas entre niveles de escolarización y ejercicio del sufragio.

\section{b) Comparación entre la Ley Nacional y el proyecto de Ley provincial $7319 / 2011$}

Por su artículo 16, la ley nacional fija los límites de la obligatoriedad:

"La educación es obligatoria en todo el país desde la edad de CINCO (5) años hasta la finalización de la escuela secundaria. El Ministerio de Educación, Ciencia y Tecnología y las autoridades jurisdiccionales competentes asegurarán el cumplimiento de la obligatoriedad escolar a través de alternativas institucionales, pedagógicas y de promoción de derechos, que se ajusten a los requerimientos locales y comunitarios, urbanos y rurales, mediante acciones que permitan alcanzar resultados de calidad equivalente en todo el país y en todas las situaciones sociales".

El Proyecto neuquino se refiere a la obligatoriedad en el capítulo I "disposiciones generales" en términos similares a la ley nacional en su artículo 12:

"La obligatoriedad escolar en todo el territorio provincial se extiende desde los cinco(5) años de edad hasta la finalización de la Educación Secundaria. Las políticas públicas provinciales deben asegurar la obligatoriedad a través de alternativas institucionales y pedagógicas que se ajusten a los principios de equidad, igualdad y calidad definidos en la presente Ley”. 
Y recupera el tema en el Título IV referido a los niveles del sistema educativo provincial en los siguientes artículos:

\begin{abstract}
“Artículo 16. El Nivel Inicial constituye el primer nivel educativo del sistema formal, que garantiza temprana atención educativa a los niños/as desde los cuarenta y cinco (45) días hasta los cinco (5) años de edad inclusive. Siendo obligatorio la sala de cinco (5) años.

Artículo 17. El Estado provincial tiene la obligación de universalizar los servicios educativos para los/as niños/as de cuatro (4) años de edad, entendiendo como universalización la responsabilidad indelegable de asegurar su provisión y regular su funcionamiento, con garantía de igualdad de oportunidades para todos/as y la extensión progresiva de los servicios educativos para los/as niños/ as de tres (3) años de edad.

Artículo 25. La Educación Primaria es obligatoria, se organiza en siete (7) años de duración y está destinada a la formación integral, de acuerdo a los principios que marca la presente Ley, de los/as niños/as a partir de los seis (6) años de edad.

Artículo 29. La Educación Secundaria es obligatoria, y destinada a los/as adolescentes, jóvenes y adultos que hayan cumplido con el nivel de Educación Primaria".
\end{abstract}

\title{
c) Registro del problema en la Ley Orgánica 2945/2014
}

En cambio la Ley Orgánica por su artículo 12 declara que "es obligatoria, en la Provincia del Neuquén, la escolarización de niñas, niños y adolescentes, desde los cuatro (4) años de edad hasta la finalización del Nivel Secundario"5. Y agrega que:

"las políticas públicas provinciales deben asegurar los medios necesarios para el cumplimiento de esta obligación, a través de alternativas institucionales y pedagógicas que se ajusten a los principios de equidad, igualdad y excelencia”.

Y en el título IV, al referirse a los niveles del sistema educativo provincial, ratifica la obligatoriedad del nivel inicial desde los 4 años, la duración de 7 años de la educación primaria obligatoria, la organización en dos ciclos y la obligatoriedad de la educación secundaria.

En el capítulo IV, dedicado a la "Educación Permante de Jóvenes y Adultos" se explicita que está "destinada a garantizar la alfabetización y el cumplimiento de la obligatoriedad a quienes no la hayan completado en la edad establecida reglamentariamente, y a brindar oportunidades formativas a lo largo de toda la vida".

${ }^{5}$ La Ley N² 27.045/14 modificó la Ley de Educación Nacional haciendo extensiva la obligatoriedad del nivel inicial a la sala de 4 años. 
Finalmente en el capítulo VII define la Educación Rural como la "modalidad del Sistema Educativo destinada a garantizar el cumplimiento de la escolaridad obligatoria, a través de formas adecuadas a las necesidades y particularidades de la población que habita en zonas rurales".

\section{d) Síntesis y prospectiva en cuanto a la obligatoriedad}

a) La negación de las vinculaciones aristocratizantes entre escolarización y prevención de la delincuencia así como nivel de escolarización como criterio de acceso y ejercicio de la ciudadanía.

b) La afirmación del papel de la escuela en la formación teórica y práctica de los derechos humanos, en particular, los referentes a la construcción de ciudadanía.

c) La superación del enciclopedismo abstracto limitado a la mera inclusión de contenidos mediante la incorporación efectiva de los estudiantes, en especial en la escuela media, en prácticas adecuadas de participación directa en el gobierno escolar.

\section{La cuestión de la gratuidad}

\section{a) Breve contextualización histórica}

Podríamos afirmar que la idea de la gratuidad de la educación se encuentra "naturalizada" en nuestro país y se hace evidente en momentos históricos de movilizaciones populares tales como las realizadas durante la década de los 90 en particular donde tomaron fuerza propuestas gubernamentales como las llamadas escuelas "charter".

Quizá a esa naturalización obedezca el relativo desconocimiento de las divergencias que existieron ya en los momentos fundacionales, por ejemplo, decía el liberal Nicomedes Antelo, en oposición a la gratuidad en el Congreso Pedagógico del '82:

\footnotetext{
"Gratuita, señores, bien pensado, quiere decir, como lo ha afirmado el señor Congresal que me ha precedido en la palabra [era el católico BialetMassé] el sistema socialista en la renta [...] El sistema que obliga al rico a pagar la educación del pobre, es el sistema socialista, no el de la democracia, no es el de la ciencia, mucho menos el de la jurisprudencia, el del derecho" (citado por Cucuzza 1985:125).
}

Prevenimos sobre posibles lecturas nostálgicas sobre los momentos fundacionales para señalar que se impusieron las posturas en favor de la 
gratuidad y rescatamos la argumentación del Dr. Pena donde se la vincula con el concepto de educación común:

"...todos los gastos de la escuela, absolutamente todos, deben salir de las contribuciones escolares que se voten y que serán administradas por las autoridades escolares. Por eso las escuelas son comunes, y por eso la enseñanza es gratuita: la pagan todos los que estén en la escuela en beneficio de todos, tanto de los que tienen fondos para pagar la instrucción como de los que no la tienen. Por eso, repito, la escuela es gratuita" (citado por Cucuzza 1985:52).

En cuanto a la enseñanza universitaria corresponde al primer peronismo el principio de la gratuidad anunciado en un discurso de Juan D. Perón el 20 de junio de 1949, en el Día de la Bandera, en homenaje al General Belgrano:

“...deseo anunciar que desde hoy quedan suprimidos los actuales aranceles universitarios en forma tal que la enseñanza sea absolutamente gratuita y al alcance de todos los jóvenes argentinos que anhelen instruirse para bien del país" (Cucuzza 1995: s/p).

El antecedente fue invisibilizado durante el menemato por el mismo Ministro de Educación Jorge Rodríguez y los mismos diputados peronistas durante el debate parlamentario de la Ley de Educación Superior No. 24.521 que abría la puerta al arancelamiento generando fuertes resistencias estudiantiles y docentes.

Finalmente creemos que debe superarse la idea de la gratuidad limitada a la oferta estatal del establecimiento y los servicios educativos atendiendo de manera especial a los sectores sociales más desfavorecidos.

\section{b)Comparación entre la Ley Nacional y el proyecto de Ley provincial 7319/2011}

El artículo $4^{\circ}$. de la Ley Nacional declara que:

"El Estado Nacional, las Provincias y la Ciudad Autónoma de Buenos Aires tienen la responsabilidad principal e indelegable de proveer una educación integral, permanente y de calidad para todos los/as habitantes de la Nación, garantizando la igualdad, gratuidad y equidad en el ejercicio de este derecho, con la participación de las organizaciones sociales y las familias”.

Y procura asegurar la efectividad de la declaración mediante una cláusula de financiamiento en su artículo $9^{\circ}$ :

"El Estado garantiza el financiamiento del Sistema Educativo Nacional conforme a las previsiones de la presente ley. Cumplidas las metas de 
financiamiento establecidas en la Ley $\mathrm{N}^{\circ} 26.075$, el presupuesto consolidado del Estado Nacional, las Provincias y la CIUDAD AUTÓNOMA DE BUENOS AIRES destinado exclusivamente a educación, no será inferior al SEIS POR CIENTO (6 \%) del PRODUCTO INTERNO BRUTO (PIB)".

Remitiremos ahora nuevamente al artículo $4^{\circ}$. del proyecto No. 7319 en el título I Principios, Derechos y garantías, que incluye el principio de la gratuidad y añade respecto de las responsabilidades del Estado provincial "asegurar, proveer y garantizar" una educación que "sea inclusiva, equitativa, integral, con justicia social y calidad".

El tema es reforzado en el artículo $6^{\circ}$. cuando se señala que:

"El Estado provincial garantiza el acceso, permanencia, egreso y recurrencia de todos/as los/as niños/as y jóvenes a la educación en todos sus niveles y modalidades".

La aplicación de estos principios generales debería garantizarse mediante la provisión de recursos suficientes como señala el artículo 90 en el Título VIII de disposiciones transitorias y complementarias cuando señala que "el financiamiento de la educación [...] deberá implementarse con el destino de obtener y contar con los recursos humanos, materiales, tecnológicos y servicios necesarios para garantizar [...] las necesidades educativas de la población haciendo cada vez más eficiente y equitativa su distribución y utilización".

Aquí incluiríamos nuestras reflexiones acerca de la ampliación de los alcances de la gratuidad, aunque se torna abstracto el planteo en tanto el artículo 91 plantea hacia adelante las cuestiones presupuestarias al indicar que la HLN "podrá (sic) sancionar una ley específica de financiamiento educativo, en la que deberá contemplar las fuentes de financiamiento, las transferencias de recursos financieros, el incremento anual y la evaluación del gasto".

En la misma esfera de expresión de deseos quedarán otros planteos sobre el tema, y citaremos en particular del Anexo I en el punto 14. Calidad y mejoramiento del servicio educativo, el inciso 14.6, que citamos en extenso:

"Facilitar el material de estudio y tecnológico a los educandos.

El Foro es una buena oportunidad para analizar y elaborar estudios de factibilidad sobre la conveniencia, financiamiento, distribución y alcance del aprovisionamiento parcial o totalmente gratuito de textos escolares y materiales de estudio y aun de procesadores informáticos, tal como lo están realizando países vecinos y otras provincias argentinas en los niveles de educación obligatoria. Subsidiaria o complementariamente será conveniente el impulso a la creación de sistemas y bolsas de préstamos y recolección de libros". 
En el mismo estatus quedaría el punto 19 referido a las "políticas públicas de acción social y salud para la igualdad de oportunidades. Su relación con el sistema educativo y la escuela":

"Es necesaria una adecuada coordinación con las políticas nacionales y provinciales, así como en concreto con los programas sociales existentes a efectos de coadyuvar en aquellos aspectos inherentes a la mejora en la calidad de vida de los educandos, condición indispensable para su desempeño en la institución educativa".

\section{c) Registro del problema en la Ley Orgánica 2945/2014}

La Ley Orgánica recupera la formulación del artículo 3 del anteproyecto al definir la educación pública como gratuita [...] y reformula el "con justicia social y de calidad" por un "con justicia social y de excelencia".

También reproduce en su artículo $5^{\circ}$ que "El Estado provincial garantiza el acceso y las condiciones para la permanencia, el egreso y la recurrencia de niñas, niños, jóvenes y adultos a la educación, en todos sus niveles y modalidades".

Aquí deseamos remarcar que en el artículo $7^{\circ}$ sobre fines y objetivos que aparecía como artículo $6^{\circ}$ en el anteproyecto, en esta formulación está directamente ligado a la gratuidad haciéndola extensiva a todos los niveles y modalidades:

"h) Garantizar el acceso y las condiciones para la permanencia y el egreso de los diferentes niveles del Sistema Educativo, asegurando la gratuidad en las instituciones de gestión estatal, en todos los niveles y modalidades".

Aunque le caben las mismas observaciones que realizáramos sobre el financiamiento de la educación al Proyecto $\mathrm{N}^{\circ} 7319$, al no fijar lineamientos para una futura Ley que, según el artículo 111 incluido en las disposiciones transitorias y complementarias:

"En el plazo de un (1) año, a partir de la promulgación de la presente Ley, se deben sancionar las siguientes Leyes: de Financiamiento de la Educación, de Educación Privada, del Observatorio del Sistema Educativo, y de Educación intercultural".

En el capítulo único sobre financiamiento educativo un llamativo artículo 100 insinúa controles sobre aportes financieros a las escuelas privadas, dice así:

"La asignación de aportes financieros por parte del Estado provincial a los establecimientos de gestión privada será regulada por una ley especial, la 
que debe tener en cuenta criterios objetivos de justicia social, tipo y función social que cumple el establecimiento, proyecto educativo y arancel que se establezca".

Quizá, la complejidad de los problemas del financiamiento educativo que refleja concepciones ideológicas y políticas con mayor claridad que un capítulo de principios generales, sea el motivo del incumplimiento del plazo de un año y de la nueva prórroga por ley del 15/7/2016, a fines de diciembre de 2017.

\section{d) Síntesis y prospectiva en cuanto a la gratuidad}

a) Negar la definición de la gratuidad limitada en sus alcances a la mera provisión estatal de edificio y maestro.

b) Afirmar las experiencias históricas de ampliación de los alcances de la gratuidad a la provisión de útiles escolares, boleto estudiantil, servicios de alimentación y salud, garantizando el financiamiento.

c) Superar las propuestas de asistencialismo escolar para adoptar iniciativas y campañas del tipo de la asignación universal por hijo, entre otras.

\section{La cuestión de la gradualidad}

\section{a) Breve contextualización histórica}

A pesar de las tentativas de las elites criollas por imponer el sistema mutuo lancasteriano en Latinoamérica se impuso en el siglo XIX el sistema simultáneo de Juan Bautista de La Salle. En ambos casos la organización del aula implicaba una reorganización del tiempo y el espacio escolares, aunque el triunfo de los Hermanos finalmente condujo al aula graduada de fines del siglo XIX que, en esencia, persiste hasta nuestros días.

Sería posible realizar estudios comparados de los numerosos intentos de superación del encierro del aula: desde las excursiones y viajes ya propuestos por Fröbel hasta las experiencias anarquistas de enseñar en el camino, desde las experiencias de Jesualdo en Uruguay, hasta las actividades de los movimientos sociales como las que realizan los zapatistas en México, las escuelas itinerantes del MST en Brasil, o el MOCASE en Argentina, desde el aula sin muros de Marshall Mcluhan a las propuestas desescolarizadoras de Ivan Illich hasta el Plan Dalton y otras experiencias escolanovistas, o desde la non graded school norteamericana a las actividades del maestro Luis Iglesias en Argentina. (Cucuzza 2012: 43-44, Padawer 2008). 
En nuestro país, fue el escolanovista Ernesto Nelson un precursor en develar los mecanismos de la selección que se desarrollan en el interior del aula señalando:

"Así, si examinamos los rodajes del mecanismo educacional vemos que en él todo gira alrededor de los conocimientos, como en un banco todas las operaciones giran en torno del dinero". (Nelson 1915: 26).

Agrega que, para mantener los rodajes en funcionamiento, el Estado dispone de un instrumental que Nelson caracteriza como integrado por cuatro elementos aunque no pudo ver que su funcionamiento se desarrolla en un aula:

“- el plan de estudios, no es otra cosa que el cuadro general de las familias de conocimientos que se suponen necesarios en la educación general del hombre; - el programa, es el catálogo detallado de dichos conocimientos, o como si se dijera, la lista de las verdades oficiales;

- el libro de texto, es el instrumento impreso que consigna y transmite esos conocimientos, y finalmente

- el examen, es el acto en que se toma cuenta al alumno de la expresión de los conocimientos adquiridos. (Ibid: 27 , negritas del autor)".

Nos extendemos en este punto para procurar problematizar en especial, en articulación con los principios fundacionales de los sistemas educativos decimonónicos euro-occidentales (gratuidad, laicidad, obligatoriedad, gratuidad), como señaláramos en la introducción, uno de los vértices escasamente trabajados: el que se refiere a la organización de los sistemas escolares en aulas graduadas que contienen cohortes de alumnos de la misma edad cronológica.

Para resumir los cuestionamientos al sistema graduado nos apoyamos en Ana Padawer la que recupera otros trabajos que señalarían tres discusiones:

“a) el etiquetamiento por grados (la presunción de que los niños de la misma edad trabajan igual académicamente),

b) el sistema de promoción-repetición (que obliga a recursar un año entero si un niño no logra demostrar su calificación en los contenidos del año en curso) y

c) el uso de sistemas de evaluación competitivos/comparativos (que implica que el producto del esfuerzo académico de un niño se califica o ranquea con símbolos de una escala de aceptabilidad)" (Padawer 2008:159).

La autora examina experiencias realizadas en nuestro país en la Provincia de Buenos Aires, en escuelas rurales bonaerenses que no se definen como multigrado y sí como no graduadas, algunas escuelas no graduadas que retoman la experiencia de Luis Iglesias (pese a que mantenía los grados en una escuela unidocente), al mismo tiempo que utilizaban materiales de la non graded school 
norteamericana; experiencias que, sometidas a estudios por medio de una comisión de expertos, podrían adoptarse adecuadas a las diferentes realidades provinciales en el mediano plazo. (Padawer 2008: pp. 156-157, cursivas de la autora).

Aquí manifestamos nuestro convencimiento sobre la relativa incidencia de la graduación como mecanismo interno de legitimación de desigualdades externas, y sus consecuencias, en última instancia, del premio del acceso y la promoción ascendente tanto como de la sanción y la exclusión en la apropiación de la cultura escrita.

Los datos estadísticos en Neuquén en el nivel primario refuerzan la necesidad de revisar los mecanismo internos de la escuela, en tanto, si bien los porcentajes de promoción señalan auspiciosos 94,20\%, en el ámbito rural aglomerado, un 90,06\%, en el ámbito rural disperso, y un 95,20 en el ámbito urbano; las mismas fuentes denuncian porcentajes de repitentes para los mismo ámbitos de 5,79\%, 8,23\% y 4,33\%, respectivamente.

Y las cifras absolutas reflejan 113, 308 y 311 para los mismos ámbitos, con un total provincial de 3.532 alumnos que no atraviesan los filtros; a los que deben sumarse los porcentajes de sobreedad que alcanzan el 22,75\% a nivel provincial como fuente probable de desgranamiento.

Prevenimos sobre una lectura "apocalíptica" de los datos seleccionados sobre el eje de la argumentación. Por razones de síntesis del presente artículo no encaramos otros estudios en profundidad comparativos en la sincronía con los datos nacionales, provinciales y regionales; así como los estudios provinciales en la diacronía que reflejarían los esfuerzos de las administraciones y, en particular de los docentes. La desagregación de los datos correspondientes al ámbito privado agrega diferencias segmentadas socio-culturales, que, en otra escala aparecerían dentro del mismo ámbito estatal, y en definitiva, en el interior de cada escuela y cada aula de clases ${ }^{6}$.

Somos concientes sobre posibles lecturas que nos adjudiquen de manera ligera posiciones "reproductivistas" al estilo Bourdieu, Passeron o Ivan Illich: no hablamos de la relación "escuela" y "sociedad" en general sino de los cotidianos procesos de enseñanza aprendizaje que transcurren en el espacio del aula, en especial, cuando se impone el tiempo de la acreditación del examen aunque esta relación merecería otros desarrrollos.

Vale aquí recuperar las hipótesis tantas veces citadas de Tyack y Cuban cuando afirmaban que:

\footnotetext{
${ }^{6}$ Todos los datos estadísticos mencionados en este informe fueron tomados de un material elaborado por la Dirección de Planeamiento, Departamento de Estadística Educativa, Secretaría de Educación, Cultura y Deportes del Consejo Provincial de Educación sobre la base de la disposición 21 de la ley 2724. Lamentablemente no poseemos referencias en internet.
} 


\begin{abstract}
"Durante el último siglo, ha habido mucha continuidad en las estructuras, reglas y prácticas que organizan la labor de la instrucción. Estas regularidades de organización (la gramática de la escolaridad) incluyen prácticas tan familiares como la graduación de los alumnos por edades, la división del conocimiento por materias separadas y el aula autónoma con un solo maestro" (Tyack, y Cuban, 2001: 23, destacado propio).
\end{abstract}

Para cerrar este apartado, nos preguntamos hasta qué punto, el registro de las continuidades, de las invariancias, de las regularidades, etc., en los sistemas educativos, no sería sino un reflejo de las preocupaciones teóricas (por lo menos a nivel euro-occidental) por el fracaso de las tentativas de reformas escolares, en definitiva, por el incumplimiento de la promesa y el descontento con el incumplimiento de la utopía de Comenio de enseñar todo a todos en todo momento.

\title{
b) Comparación entre la Ley Nacional y el proyecto de Ley provincial $7319 / 2011$
}

Así como no aparece expresamente la mención a la gradualidad (salvo en la estructuración del sistema donde se habla de "años") tampoco aparece la mención a la organización en ciclos dentro de cada nivel o modalidad, salvo en la formación docente y en la educación rural, en este caso en el artículo $49^{\circ}$.

Inciso a):

"Permitir modelos de organización escolar adecuados a cada contexto, tales como agrupamientos de instituciones, salas plurigrados y grupos multiedad, instituciones que abarquen varios niveles en una misma unidad educativa, escuelas de alternancia, escuelas itinerantes u otras, que garanticen el cumplimiento de la obligatoriedad escolar y la continuidad de los estudios en los diferentes ciclos, niveles y modalidades del sistema educativo, atendiendo asimismo las necesidades educativas de la población rural migrante." (subrayado propio)

El problema de la recuperación del retraso en los aprendizajes aparece explícitamente en el proyecto provincial de manera de evitar que formas de acreditación se posterguen hacia el final de un ciclo postergando en ese caso el registro del fracaso escolar.

Merecen citarse en extenso las recomendaciones del anexo I, aunque señalamos que su inclusión en el subtítulo 9.3, La Educación Especial podría remitir a concepciones que patologizan el retraso escolar que ocultan el peso de las diferencias socio-culturales en el acceso y permanencia en el sistema educativo: 
“9.3.9. Establecer mecanismos de atención permanente para niños de primer ciclo de primaria con problemas de aprendizaje de distinto orden. Se procura para ellos una asistencia especial y personalizada a efectos de integrarlos progresivamente. Se formula así la necesidad de establecer la "Pareja Pedagógica" para el primer ciclo. Se entiende a este docente con las características de la "Maestra de Apoyo" o "Recuperadora".

9.3.10. Se propone la creación de la figura de un "Docente Tutor Facilitador" para colaborar con el docente del aula y realizar seguimiento de los alumnos.

9.3.11. Diagramar un plan de formación permanente de las "Maestras de Apoyo" para la mejora de las prácticas educativas y la consolidación del trabajo en la modalidad de Pareja Pedagógica. Esta capacitación se desarrolla mediante actividades de taller.

9.3.12. Implementar en el ámbito del CPE el proyecto de "Pareja Pedagógica", para atender a la diversidad de las Escuelas Primarias para Adultos Especiales en aquellas que se da cumplimiento a la Disposición 09/04 del CPE.

9.3.13. Prevé la constitución de equipos interdisciplinarios que funcionarán en cada zona de supervisión escolar. El equipo interdisciplinario debe recepcionar, atender y acompañar a niños adolescentes y adultos escolarizados en situaciones psicosociales y pedagógicas que lo requieran.

"9.3.9. Establecer mecanismos de atención permanente para niños de primer ciclo de primaria con problemas de aprendizaje de distinto orden. Se procura para ellos una asistencia especial y personalizada a efectos de integrarlos progresivamente. Se formula así la necesidad de establecer la "Pareja Pedagógica" para el primer ciclo. Se entiende a este docente con las características de la "Maestra de Apoyo" o "Recuperadora"."

\section{c) Registro del problema en la Ley Orgánica 2945/2014}

Tampoco encontramos mención alguna a la organización en grados en la Ley Orgánica aunque se sobreentiende la organización en años no se mencionan ciclos en primaria aunque sí en secundaria referidos a contenidos curriculares.

No aparecen mencionadas las estrategias que desarrolla en extenso el Proyecto 7319 al que dimos un amplio espacio en el apartado anterior cuando se refiere a la Educación Especial.

Podría suponerse que a ellas se hace referencia en el punto inciso e) del título II sobre fines y objetivos cuando reclama:

"Garantizar la inclusión educativa, a través de políticas universales y de estrategias pedagógicas y de asignación de recursos que otorguen prioridad a los sectores más desfavorecidos de la sociedad".

\section{d) Síntesis y prospectiva en cuanto a la gradualidad}

a) Negar la organización del aula frontal graduada en lo que hace a sus mecanismos internos de acreditación para la promoción bajo el supuesto de la igualdad de los alumnos ante las prácticas escolares comunes. 
b) Afirmar la necesidad de prácticas diferenciadas de organización en ciclos especialmente en los primeros años de la escuela primaria y de la escuela secundaria, que compensen las desigualdades de origen social y familiar en el acceso a la cultura letrada.

c) Superar el fracaso escolar consecuente y sus expresiones en la repetición, el desgranamiento y la deserción mediante la adopción de formas variadas de recuperación del retraso sin que ello implique la patologización generadora de ghetos de repitentes.

\section{Algunas reflexiones para continuar el debate}

En el transcurso de este viaje a vuelo de pájaro sobre la historia de la educación argentina realizado en función de situar en contexto histórico los debates de la Provincia del Neuquén, se observa, ya desde los momentos fundacionales y en el transcurso del siglo XX hasta nuestros días, una lucha de hegemonías contrastantes en las políticas educativas donde los sectores dominantes no logran imponer sus proyectos hegemónicos ni los sectores subalternos proyectos alternativos. Una suerte de "empate hegemónico". (Portantiero 2013).

La resistencia a las sucesivas reformas en el siglo XX se dio desde posiciones "defensivas" (defensa de la Ley 1420, defensa del laicismo, etc.). La elaboración de propuestas alternativas comienza a vislumbrarse durante las luchas contra la reforma Onganía-Astigueta a través de diversos movimientos sociales y se afianza con la constitución de CTERA y otras organizaciones de padres y maestros.

Pueden destacarse seis momentos donde se intensifica la lucha ideológica: los orígenes del sistema, la reforma Saavedra Lamas, el primer peronismo, la reforma Onganía-Astigueta, las movilizaciones contra la Ley Federal Menem/ Sajonia, y la puesta en marcha de la ley Kirchner/Filmus; y es posible aventurar su reintroducción durante las tentativas que se realicen en cada jurisdicción, tal el caso del Neuquén.

A pesar de los momentos de imposición hegemónica diversas formas de resistencia pueden registrarse en los niveles institucionales dando lugar a ensayos y experiencias innovadoras tanto como a rechazos a las tentativas de cambio desde posiciones docentes conservadoras.

Es posible afirmar que las formas de la segmentación adquirieron su forma extrema de fragmentación de manera desigual en las distintas jurisdicciones nacionales a partir de la Ley 24049 de 1991 que fijaba la transferencia de los servicios educativos de la Nación a las provincias y Municipalidad de la Ciudad de Buenos Aires. 
La desarticulación del sistema era registrada por Adriana Puiggrós al referirse a la aplicación desigual de la Ley Federal de Educación hacia 2005. Decía:

"La nueva estructura se impuso de manera dispar. Hoy la Argentina presenta varios modelos de sistemas escolares insuficientemente articulados: dos ciclos de 6 años (Córdoba), 9 años de EGB y tres de Polimodal (el 65\% de las escuelas de la Pcia. De Buenos Aires); el tercer ciclo disociado tanto de primeros como del Polimodal (en escuelas de casi todas las provincias); y la antigua (y caduca) estructura sin reformas (Ciudad Autónoma de Buenos Aires). Cabe subrayar que estos modelos coexisten en algunas provincias cual son Mendoza y Buenos Aires.” (Puiggrós 2005: 191).

La Provincia del Neuquén a su vez, había suspendido por decreto 1712/00 la Ley Federal desde el año 2000 sumándose a la CABA que nunca la había adoptado.

Las transferencias abrieron un amplio margen de acción a las jurisdicciones provinciales, más allá que su realización en los noventa fueran realizadas en consonancia con las políticas privatizadoras fundadas en las concepciones de la subsidiariedad del Estado y permitieron ensayar propuestas alternativas particulares regionales, como este ensayo de Ley Orgánica que consideramos.

El principal objetivo económico de las transferencias aparece en los trabajos de diversos autores como Alejandro Morduchowicz:

"Frente a esta propuesta, conviene introducir la idea de descentralización por desesperación (Arango, 1993). Este concepto implica que, ante un deterioro extremo de las capacidades del sector público, parecería mejor transferir sus funciones a las provincias o al mercado antes que embarcarse en el complejísimo proceso de reconstruirlas." (Morduchowicz 2009: 22; Cao, 2011) ${ }^{7}$.

Y en un párrafo que muestra con claridad el optimista clima del breve interregno de los tiempos postnoventistas señalaba Juan Carlos Tedesco frente al problema que:

"Estamos en consecuencia frente a un escenario que demanda mucho más que en el pasado una acción pública destinada a promover mayor participación, pero también mayor homogeneidad en los resultados y mayor cohesión nacional frente a la fragmentación que caracteriza el funcionamiento del sistema educativo [...] pero más cohesión, el problema central se refiere a la articulación entre el Estado nacional y las provincias" (Tedesco 2005: 23) ${ }^{8}$.

\footnotetext{
${ }^{7}$ Una abundante bibliografía cubre este tema que no estamos en condiciones de abordar en este artículo. Ello no impide alguna mínima reflexión acerca de la metáfora de descentralización por desesperación: en todo caso sólo atiende a las condiciones de los productores de dichas políticas educativas pero desatiende a sus receptores en cuyo caso podría ser reformulada como descentralización para la desesperación por sus dramáticas consecuencias en las mal llamadas provincias pobres.

${ }^{8}$ Para más datos decía Tedesco en el mismo artículo que "Ya parece superada la tentación de
} 
Finalmente, y recuperando reflexiones desarrolladas en los ejes de los ítems que hemos analizado, diremos que:

El actual panorama latinoamericano de restauración conservadora y hegemonía neoliberal no autoriza el optimismo que registráramos en Juan Carlos Tedesco a comienzos del siglo XXI, en 2005.

Alcanzaría con registrar el salto al vacío producido desde 1979 (México), cuando UNESCO aprobó el Proyecto Principal de Educación (PPE) que propuso alcanzar tres metas para el año 2000: acceso universal a la escuela primaria, eliminación del analfabetismo adulto y mejoría de la calidad y la eficiencia de la educación; hasta que pasada la euforia milenarista, llegáramos al documento "Metas educativas 2021: la educación que queremos para la generación de los Bicentenarios" redactado durante la XVIII Conferencia Iberoamericana de Educación celebrada en El Salvador en mayo de 2008, cuando se prorroga el plazo para un todavía lejano 2021.

Sobre nuestro país en particular, Myriam Southwell y Alejandro Vassiliades al encarar un trabajo sobre las articulaciones y disputas en la trama entre trabajo docente e igualdad educativa, realizan una aproximación histórica sugerente para analizar tres momentos, a saber:

a) El período fundacional de la construcción del sistema, la Ley 1420, el normalismo; en el que igualdad e inclusión se entrelazaban configurando el trabajo docente en términos de homogeneización de los sujetos anulando las diferencias vistas como amenazas o peligrosas. La inclusión excluyente a la que nos referíamos en la introducción.

b) Por otra parte los mecanismos de regulación de la dictadura cívico-militar desde 1976 desplazarían el valor de la igualdad hacia lógicas particularistas que negaban la noción de lo común y de la igualdad. La modernización como adaptación de la escolarización a las demandas del entorno, si quizá fuera su máxima expresión fue ocultada por el despliegue del terror dictatorial.

c) $\mathrm{Y}$ en cuanto a las reformas de los ' 90 profundizarían la desigualdad enfatizando los mecanismos particularizantes y nuevas regulaciones del trabajo docente. Provocaron una ausencia del valor de la igualdad y un refuerzo de las injusticias de la distribución. Dichas ausencias concluyen los autores "han ido de la mano de la promoción celebratoria de las diferencias como un aspecto nodal del discurso neoliberal" (Southwell y Vasilíades, 2016:50).

Por último, una lectura atenta de las breves comparaciones entre la Ley de Educación Nacional y los dos documentos de la Provincia del Neuquén evidencia las insinuaciones del título acerca de los acordes y disonancias en las

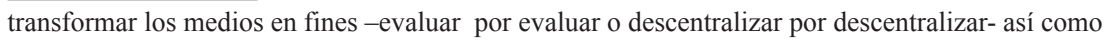
parece superada la idea de bajar los costos como gran objetivo de la reforma" (Ibid: 34) 
relaciones entre Nación y Provincias. Por ejemplo, acordes en la definición de ciclos y modalidades y fuerte disonancia respecto de la laicidad.

Atraviesan nuestra historia las pugnas entre centralismo y federalismo originadas en disputas hegemónicas que también se expresaron en las políticas educativas, y por ende, en las legislaciones resultantes de antagónicos modelos de país.

Valga repensar en la antinomia Nación vs Provincias en forma simultánea los tres momentos de la dialéctica, como ensayamos en los párrafos titulados síntesis y prospectiva. Así:

a) Se impone recuperar/conservar las políticas estatales en favor de la educación pública con inclusión en función de la integración ciudadana y la identidad nacional respetuosa de las diferencias regionales, de género y de los pueblos originarios.

b) Para ello rechazar/suspender tanto el centralismo basado en la histórica hegemonía portuaria porteña como las formas seudofederativas que ocultan permanencias de estructuras cuasifeudales y sus consecuencias en la educación.

c) Para alcanzar/superar articulaciones que no opongan la homogeneidad con la diversidad ni viceversa, sobre la base de lógicas equitativas de coparticipación federal de los recursos financieros que permitan garantizar la educación pública obligatoria en todo el país.

Aunque pueda sonar utópico, quizá sean esperanzadoras las escenas del Bicentenario de las Independencias Latinoamericanasen 2017,si la celebración se abre a la imaginación de la nueva educación pública. 


\section{Referencia bibliográficas:}

Brener, Gabriel y Galli, Gustavo (comp), Introducción. En Brener, Gabriel y Galli, Gustavo Inclusión y calidad como politicas educativas de Estado o el mérito como opción única de mercado, Buenos Aires, Crujía, Stella, Lasalle, 2016, pp. 9-18.

Cantini, José Luis y otros, Bases y alternativas para una Ley Federal Educación, EUDEBA, Buenos Aires, Universidad Nacional de Buenos Aires/ Universidad Nacional de Rosario, coedición, primera edición, 1981.

Cao, Claudia, Las reformas del gobierno y la gestión del Sistema Educativo: debate parlamentario de la Ley de Educación Nacional (2006), Anuario de Historia de la Educación, vol. 12, no. 1, Sociedad Argentina de Historia de la Educación, 2011. http://www.scielo.org.ar/scielo.php?script=sci arttext\&pid=S2313-92772011000100005\&lng=es\&nrm=iso\&tlng=es

Cucuzza, Héctor Rubén, El sistema educativo argentino. Aportes para la discusión sobre su origen y primeras tentativas de reforma. En Hillert, Flora y otros: El sistema educativo argentino. Antecedentes, formación y crisis, Bs. As., Cartago,1985, pp. 103-137.

Cucuzza, Héctor Rubén, De congreso a Congreso. Crónica del 1er. Congreso Pedagógico Argentino, Bs. As., Besana, 1986.

Cucuzza, Héctor Rubén, Discursos sobre educación de Juan D. Perón, Biblioteca Reservada Peronista, Colecciones especiales de la Biblioteca del Congreso de la Nación, Universidad Nacional de Luján, 1995, (mimeo).

Cucuzza, Héctor Rubén, Introducción. En Cucuzza, Héctor Rubén y Spregelburd, Roberta Paula (dir) Historia de la lectura en Argentina, Buenos Aires, Editoras del Calderón, 2012, pp. 9-49.

Juliá, Dominique, A cultura escolar como objeto histórico. En Revista Brasileira de História da Educação, No 1. Campinas, Editora Autores Associados, 2001.

Mayochi, Enrique Mario y Van Gelderen, Manuel Alfredo, Proyecto de Ley del Ministro Saavedra Lamas sobre reforma de la Ley 1420, en Fundamentos constitucionales del sistema educativo argentino, Buenos Aires, Estrada, 1969, pp.80-85.

Morduchowicz, Alejandro, El Federalismo fiscal-educativo argentino, Paris, IIPE-UNESCO, 2009.

http://www.buenosaires.iipe.unesco.org/sites/default/files/Financiamiento seminario_2008.pdf

Nelson, Ernesto, Plan de reformas a la enseñanza secundaria, Buenos Aires, La casa de los Maestros, 1915. 
Padawer, Ana, Cuando los grados hablan de desigualdad. Una etnografía sobre iniciativas docentes contemporáneas y sus antecedentes históricos, Buenos Aires, Editorial Teseo,2008.

Pitelli, Cecilia y Somoza Rodríguez, Miguel, La enseñanza religiosa en las escuelas públicas durante el primer peronismo. En Cucuzza, Héctor Rubén (dir), Estudios de Historia de la Educación durante el primer peronismo (1943-1955), Bs. As., Editorial Los Libros del Riel, 1997, pp. 41-113.

Portantiero, Juan Carlos, Clases dominantes y crisis políticas en la Argentina actual, biblioteca virtual universal, 2003. En http:/www.biblioteca.org.ar/ libros/656182.pdf

Puiggrós, Adriana, Hacia un sistema educativo nacional de base federal y democrática. En Tedesco, Juan Carlos (comp.) ¿Cómo superar la desigualdad y la fragmentación del sistema educativo argentino?, Bs.As., IIPE-UNESCO, 2005, pp.183-212.

Soutwell, Myriam y Vasilíades, Alejandro, Articulaciones y disputas en la trama entre trabajo docente e igualdad educativa: una aproximación histórica. En Brener, Gabriel y Galli, Gustavo (comp), Inclusión y calidad como politicas educativas de Estado o el mérito como opción única de mercado, Buenos Aires, Crujía, Stella, Lasalle, 2016

Tedesco, Juan Carlos, Educación y sociedad en la Argentina (1880-1945), Bs. As., Siglo XXI de Argentina, cuarta edición,2003.

Tedesco, Juan Carlos (comp.) ¿Cómo superar la desigualdad y la fragmentación del sistema educativo argentino?, Bs.As., IIPE-UNESCO, 2005.

Tyack, David y Cuban, Larry, En busca de la utopía. Un siglo de reformas de las escuelas públicas, FCE, México, 2001.

\section{Fuentes legislativas:}

Legislatura Provincia del Neuquén Foro Educativo Neuquino. Documento Base, Neuquén, HLN, 2011, s/p.

http://www.8300.com.ar/wp-content/uploads/2010/07/Proy6823-ForoEducativo.pdf

Legislatura Provincia del Neuquén Proyecto No. 7319. Ley Orgánica de Educación de la Provincia del Neuquén, Expte. D-304/11, Neuquén, Editado en Diario de Sesiones HLN, 2011, https:/www.legislaturaneuquen.gob. ar/SVRFILES/hln/documentos/DiaSesio/XL/DXL_30.pdf

Legislatura Provincia del Neuquén, Ley Orgánica de Educación de la Provincia del Neuquén, Ley 2945, 2014, https://www.legislaturaneuquen.gob.ar/ svrfiles/Neuleg/normaslegales/pdf/LEY2945.pdf 
Ministerio de Educación de la Nación, Ley de transferencias educativas 24049, 1991, http://servicios.infoleg.gob.ar/infolegInternet/anexos/0-4999/448/ norma.htm

Ministerio de Educación de la Nación, Ley Federal de Educación № 24.195, 1993, http://www.bnm.me.gov.ar/giga1/normas/4572.pdf

Ministerio de Educación de la Nación, Ley de Educación Nacional 26.026, 2006. http://www.me.gov.ar/doc_pdf/ley_de_educ_nac.pdf 